\title{
Existe escasa evidencia que respalde los tratamientos conservadores de la cervicalgia
}

Conservative management of mechanical neck pain: systematic overview and meta-análisis. Aker PD, Gross AR, Goldsmith CH et al. BMJ 1996; 313:1291-6.

\section{Objetivo}

Evaluar la eficacia del manejo conservador de la cervicalgia de origen mecánico.

\section{Fuente de datos}

Reportes publicados y no publicados identificados por dos investigadores independientes tras una amplia búsqueda manual y computarizada de bases de datos bibliográficas, referencias de artículos primarios y cartas a autores, agencias, fundaciones y comités de expertos en la materia.

\section{Selección de estudios}

Realizada en forma ciega al resumen, resultados, discusión y conclusiones. Se incluyeron ensayos randomizados y controlados que reportaran resultados de dolor como resultado principal del tratamiento conservador de la cervicalgia aguda de origen mecánico (incluida lesiones tipo latigazo) y crónica en adultos. La definición de cervicalgia de origen mecánico excluyó asociaciones con déficits neurológicos, ce- falea sin cervicalgia, o cervicalgias de otro origen (inflamatorio, neurológico, tumoral, infeccioso y por fractura o luxación). Los estudios se leccionados fueron clasificados por tres investigadores independientes según calidad metodológica.

\section{Extracción de datos}

Los puntajes de dolor fueron obtenidos de los estudios seleccionados y transformados a una escala de 100 puntos.

\section{Resultados Principales}

Cumplieron los criterios de selección 24 ensayos clínicos randomizados: Se incluyeron estudios de fisioterapia. farmacoterapia y de educación al paciente (ver Tabla). Sólo 5 de los estudios de tratamiento manual asociados a drogas, educación o fisioterapia pudieron combinarse por su homogeneidad. De ellos surge que luego de 1-4 semanas hubo una mejoría del dolor, respecto al grupo control, de 16 puntos en la escala de 100. Esto representó una reducción del $40 \%$ del puntaje de dolor basal.

\section{Conclusiones}

Existe poca información proveniente de ensayos clínicos que avalen la mayoría de los tratamientos de la cervicalgia de origen mecánico.

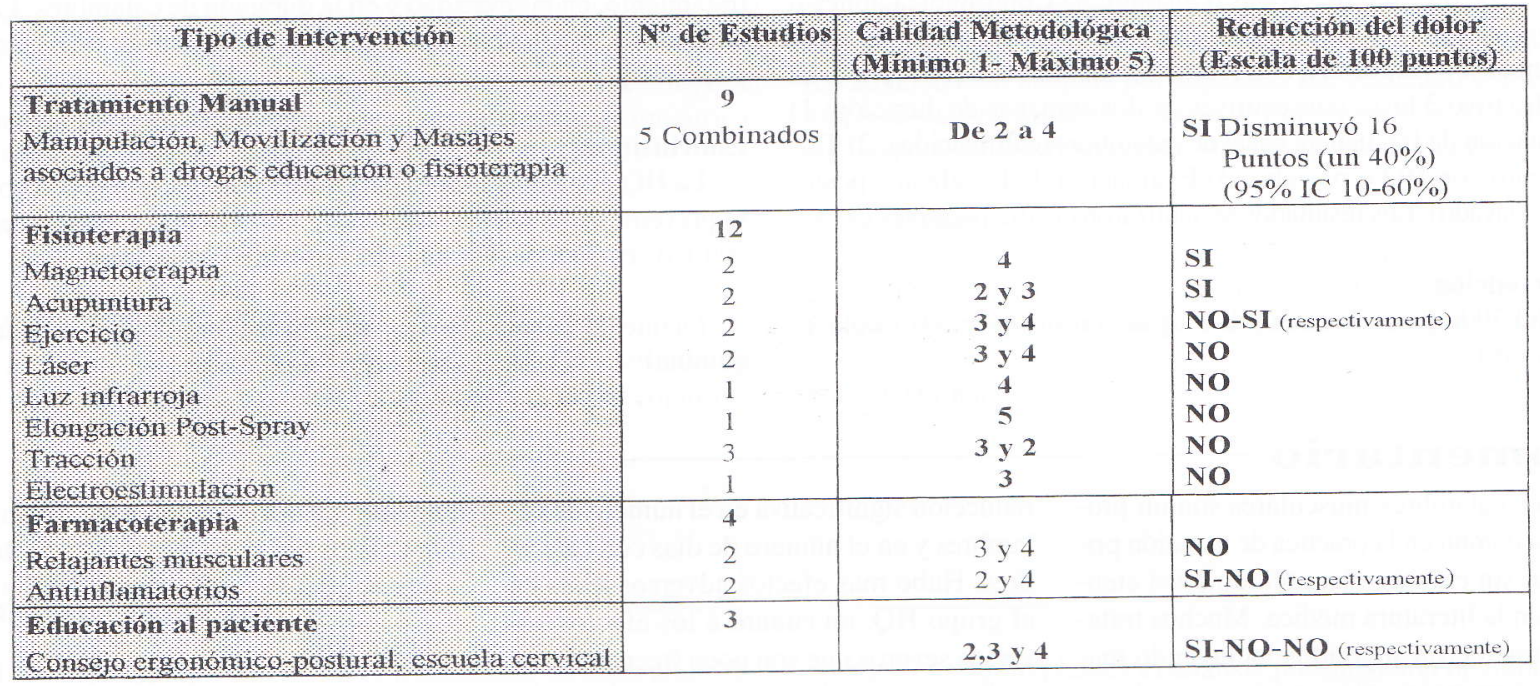

\section{Comentario}

A pesar de que la cervicalgia es uno de los problemas más comunes en atención primaria (incidencia a lo largo de la vida cercana al 50\%)(1) existe escasa evidencia acerca de la eficacia* o efectividad* de las intervenciones. Varios aspectos dan fuerza a este meta-análisis*. La fuente de datos es clara, completa e incluyó reportes no publicados, evitando el sesgo de publicación (se publican con más frecuencia estudios con resultados positivos). La definición del tema fue precisa, se realizó análisis de sensibilidad* y se aplicaron estrictos criterios de selección y calificación metodológica en forma independiente y ciega al resultado. Se demostró fundamentalmente que, exceptuando el tratamiento manual asociado a otras terapias, falta evidencia para la mayoría de las estrategias usualmente utilizadas en cervicalgias. Por ejemplo en la mayor parte de los estudios el tamaño del efecto no pudo calcularse, los estudios negativos carecían en general de poder estadístico y los efectos adversos no fueron bien documentados (sólo 16 de 1.254 pacientes, en 21 ensayos randomizados, aumentaron los síntomas o presentaron efectos adversos). Esta faita de evidencia, parecen contraponerse con la percepción de los médicos de que ejercicios. tracción y electroestimulación son los mejores métodos para tratar las cervicalgias (2). El mayor problema de los estudios evaluados es la falta de un resultado principal más clínicamente relevante como podría ser el do- lor discapacitante, parcialmente discapacitante o no discapacitante; o quizás el ausentismo laboral. Medir el dolor con una escala de 100 puntos tiene más probabilidad de encontrar diferencias significativas. Esto nos deja la incertidumbre de qué representan para nosotros y nuestros pacientes una disminución de 16 puntos en dicha escala. Las limitaciones encontradas tras esta exhaustiva revisión sistemática de la literatura deberían alentarnos a desarrollar futuros estudios, metodológicamente adecuados, para determinar las estrategias más apropiadas en el manejo de las cervicalgias.

* Ver glosario

Dr. Agustín Ciapponi Unidad de Medicina Familiar y Preventiva Hospital Italiano de Buenos Aires

\section{Referencias}

1.Bovim G, Schrader H, Sand T. Neck pain in the general population. Spine 1994;19:1307-9.

2.Rush PJ, Shore A. Physician perception of the value of physical modalities in the treatment of musculoskeletal disease. BR J Rheumatol 1994:33:566-8. 